\title{
Efeitos de inundações temporárias do solo em plantas de ervilha ${ }^{1}$
}

\author{
Jocelito S. de Sá ; Décio Eugênio Cruciani ${ }^{3}$ Keigo Minami ${ }^{4}$
}

ESALQ/USP, Av. Pádua Dias, 11, C. Postal 09, 13418-900 Piracicaba-SP; ${ }^{2}$ Doutorando em Irrigação e Drenagem; E-mail: jssa@esalq.usp.br; ${ }^{3}$ Depto. Eng. Rural, E-mail: cruciani@esalq.usp.br; ${ }^{4}$ Depto. Produção Vegetal, E-mail: kminami@esalq.usp.br

\section{RESUMO}

A cultura de ervilha é uma possível opção para a utilização dos solos de várzea durante o inverno. Porém, esta cultura não está adaptada a condições extremas de falta ou de excesso de água no solo. Nos solos hidromórficos, freqüentemente ocorrem inundações temporárias ou contínuas, afetando diretamente o desenvolvimento da planta. Neste trabalho avaliou-se o efeito da velocidade de rebaixamento do nível freático no desenvolvimento e na produtividade de plantas de ervilha, cv. Axé e determinou-se o estádio de desenvolvimento da cultura com maior sensibilidade ao excesso de água no solo. As análises dos resultados indicam que os efeitos provocados pela inundação do solo e subsequente rebaixamento do nível freático foram proporcionais à duração dos tratamentos, principalmente no estádio vegetativo. A maior suscetibilidade das plantas de ervilha à inundação do solo foi verificada no estádio reprodutivo, com reduções significativas da produtividade em todos os tratamentos. No estádio vegetativo, os rebaixamentos do nível freático em profundidades superiores a $20 \mathrm{~cm}$ por dia ocasionaram reduções da produtividade de aproximadamente $20 \%$.

Palavras chave: Pisum sativum L., drenagem, sensibilidade à inundação, deficiência de oxigênio.

\begin{abstract}
Effects of temporary waterlogging in pea plants

Pea crop is a feasible option for agriculture in low lands during winter season. However, this crop is not adapted to extreme conditions of water deficit or excess. In hidromorfic soils, temporary waterlogging or flooding conditions often occur affecting directly plant growth. The effect of water level drawdown on the growth and yield of pea, cv Axe, and the most sensitive growing stage of the crop to soil water excess were estimated. The effects of waterlogging and water table drawdown were proportional to flooding time, especially when waterlogging occurred at the vegetative stage. The major susceptibility of the pea plants to waterlogging was in reproductive stage, with significant yield reduction in all treatments. On the other hand, we observed that drawdown velocity had no effect on results, but on vegetative stage when a water level lowering in depths of more than $20 \mathrm{~cm}$ per day caused crop yield reductions of nearly $20 \%$.
\end{abstract}

Keywords: Pisum sativum L., drainage, waterlogging sensibility; oxygen deficiency

\section{(Recebido para publicação em 8 de outubro de 2002 e aceito em 18 de setembro de 2003)}

$\mathrm{O}$ cultivo de arroz irrigado é a prin cipal forma de exploração dos solos de várzea da região sul do Brasil. $\mathrm{O}$ plantio continuado desta cultura tem como conseqüência o aumento da infestação de invasoras, como o arroz vermelho e o arroz preto, o que pode impossibilitar o uso consecutivo da área. Normalmente, o método adotado para reduzir a infestação de invasoras é a ocupação da área por 2 a 3 anos com a pecuária de corte. Esta prática tem sido adotada com sucesso por muitas décadas, mas atualmente é considerada economicamente inviável, devido ao baixo rendimento dado a sub-utilização da área e da infra-estrutura. Neste contexto, situa-se como uma alternativa viável o plantio de culturas como aveia, batata, ervilha, feijão, milho, trigo e soja em rotação e, ou, em sucessão ao arroz irrigado. No entanto, estas culturas não estão adaptadas a variações extremas de umidade, provocadas por freqüentes inundações temporárias ou contínuas, ocasionadas principalmente por precipitações excessivas e pela deficiente drenagem natural. Nestas condições, o excesso de umidade interfere na aeração do solo, diminuindo a disponibilidade de oxigênio para a planta.

A redução de $\mathrm{O}_{2}$ no solo causa distúrbios funcionais em toda a planta afetando principalmente, a absorção de água e de nutrientes pelas raízes (Glinski e Stepniewski, 1986). A deficiência de $\mathrm{O}_{2}$ nos solos inundados, especialmente nos solos ácidos, pode ocasionar toxidez às plantas, principalmente pelo excesso de Fe e Mn e pelo acúmulo de substâncias fitotóxicas como dióxido de carbono e etileno (Silva, 1986; Rodrigues et al., 1993). Em estudo realizado com milho, Cruciani (1985) constatou que após 2 horas de inundação, a concentração de $\mathrm{CO}_{2}$ elevou-se de 1 para $35,5 \%$ e em 216 horas a concentração de $\mathrm{CO}_{2}$ no solo aumentou para $64 \%$.

Em resposta à redução de $\mathrm{O}_{2}$ e do aumento da concentração de gases tóxicos no solo, a planta apresenta sintomas como murchamento, clorose das folhas, hipertrofia do caule, alterações morfoanatômicas, diminuição do crescimento e da produtividade e morte das raízes (Bradford e Yang, 1981; Kramer, 1983).

As culturas apresentam diferentes tolerâncias ao excesso de umidade do solo. Espécies hidrófitas, como o arroz e algumas gramíneas, se desenvolvem normalmente em solos inundados. Por outro lado, as culturas mesófitas apresentam um comportamento variável em relação à falta de oxigênio. A tolerância à inundação do solo, apresentada por algumas culturas, pode estar relaciona-

1 Parte da Dissertação de Mestrado do primeiro autor, Depto. Eng. Rural, ESALQ/USP 
da com a capacidade das plantas em desenvolverem sistemas de raízes adventícias, aerênquimas e espaços intracelulares maiores (Sena Gomes e Kozlowski, 1980; Kawase 1981). Estas modificações morfo-anatômicas permitem a difusão do oxigênio da parte aérea da planta para as raízes, mantendo temporariamente o processo de respiração aeróbia.

Diferente de outras culturas mais tolerantes à inundação como milho e soja, a ervilha falha na produção de raízes adventícias (Jackson e Kowalewska, 1983). Testes de tolerância à inundações do solo durante o desenvolvimento de plantas de ervilha, indicaram elevada sensibilidade dessa cultura à inundação do solo por mais de 24 horas (Cannell et al., 1979). Ainda, foi constatado o surgimento de doenças como a podridão de raízes, causada por Fusarium solani f. pisi, Phytophthora spp, Rhizoctonia solani, Sclerotinia sclerotiorum e outros (McDonald e Dean, 1996). Cultivando ervilha em solo infestado com Fusarium oxysporum e Fusarium solani, Tu (1994) concluiu que a inundação dos solos pode ser um método efetivo para o controle do Fusarium.

Segundo observações de Carvalho et al. (1980) e Ferreira e Garrido (1980), a ervilha pode ser uma opção para o aproveitamento de áreas de várzea no inverno. Contudo, ainda são poucas as informações a respeito do efeito do encharcamento do solo em leguminosas na literatura, ao contrário do que se conhece sobre o efeito do déficit hídrico.

Neste trabalho avaliou-se o efeito da velocidade de rebaixamento do nível freático no desenvolvimento e na produtividade de plantas de ervilha, cv. Axé e o estádio de desenvolvimento da cultura com maior sensibilidade ao excesso de umidade no solo, dentro das condições experimentais propostas.

\section{MATERIAL E MÉTODOS}

O experimento foi conduzido em casa de vegetação do tipo arco com 8,0 $\mathrm{m}$ de largura, 20,0 $\mathrm{m}$ de comprimento e pé direito de $4,0 \mathrm{~m}$, pertencente à ESALQ em Piracicaba (SP). As unidades experimentais foram constituídas por tubos de concreto impermeabilizados com $0,4 \mathrm{~m}$ de diâmetro interno e 1,2 $\mathrm{m}$ de altura, adaptados especialmente para o experimento. Os mesmos foram preenchidos com solo classificado como Latossolo Vermelho, fase arenosa, série Sertãozinho, com $22 \%$ de argila, $8 \%$ de silte e $70 \%$ de areia. $\mathrm{O}$ solo foi retirado do seu perfil natural, na profundidade de 0 a $20 \mathrm{~cm}$, previamente peneirado e homogeneizado.

Para o cultivo da ervilha, cv. Axé, cada unidade experimental recebeu 16 $\mathrm{kg}$ de $\mathrm{N} ; 100 \mathrm{~kg}$ de $\mathrm{P}_{2} \mathrm{O}_{5} ; 40 \mathrm{~kg}$ de $\mathrm{K}_{2} \mathrm{O}$ e $4 \mathrm{~kg}$ de boro e zinco por hectare, divididos em 4 aplicações: no plantio, após a emergência e em intervalos de 10 dias. A cultivar Axé (Embrapa Hortaliças) apresenta ciclo de desenvolvimento curto (80 dias), porte ereto e é mediamente resistente ao oídio. Antes da semeadura as sementes foram tratadas com uma mistura de fungicidas na dose de 4,0 g/ $\mathrm{kg}$ de sementes e foram inoculadas com inoculante turfoso na proporção de 0,4 $\mathrm{kg} / 20 \mathrm{~kg}$ de sementes.

Foram semeadas seis sementes por unidade experimental, na profundidade de $3 \mathrm{~cm}$ aproximadamente com o solo previamente umedecido. A semeadura ocorreu em 28/05/01 e o desbaste foi realizado vinte dias após a emergência (DAE), deixando-se três plantas por umidade. Para o controle do oídio e de pragas como tripes, pulgão da ervilha e lagarta falsa medideira, foram realizadas aplicações de defensivos agrícolas segundo as recomendações de Giordano (1997). A colheita foi realizada a partir de 80 DAE, quando as vagens apresentaram coloração verde clara.

$\mathrm{O}$ efeito causado pelas diferentes velocidades de rebaixamento do nível freático (NF) foi obtido pela metodologia anteriormente utilizada por Cruciani (1985) com modificações. Os tratamentos consistiram na inundação do solo no estádio vegetativo (V) e reprodutivo $(\mathrm{R})$ da cultura, seguido do rebaixamento progressivo do NF efetuado em 10; 20; 30; 40 e $60 \mathrm{~cm}$ por dia. $\mathrm{O}$ delineamento experimental adotado foi o inteiramente casualizado, arranjado em esquema fatorial $(2 \times 5)$ com 4 repetições, além do tratamento controle.

As plantas foram submetidas ao estresse hídrico uma vez no momento em que atingiam o estádio fenológico estabelecido. A inundação das unidades no estádio vegetativo ocorreu aproximadamente aos $44 \mathrm{DAE}$, quando as plantas apresentavam as características do estágio IV descrito por Makasheva (1973) e no estádio reprodutivo quando as plantas apresentavam as características do estágio $\mathrm{X}$, o que ocorreu aos 65 DAE.

No momento da inundação, manteve-se uma lâmina de água de aproximadamente 2,0 cm acima da superfície do solo, durante 6 horas, com exceção do tratamento controle, que era somente irrigado. Para promover a inundação, reservatórios cilíndricos de PVC com $0,30 \mathrm{~m}$ de diâmetro, providos com chave bóia, foram instalados em suportes metálicos fixados por parafusos em caibros de madeira localizados ao lado de cada unidade. O manejo do NF era realizado por intermédio do rebaixamento do reservatório cilíndrico a cada 6 horas até a profundidade de $90 \mathrm{~cm}$. Após, realizava-se a drenagem total do lisímetro.

O controle da irrigação foi realizado por tensiômetros, instalados em uma das repetições de cada tratamento, na profundidade de $20 \mathrm{~cm}$. O manejo da irrigação foi fundamentado em um turno de rega de 3 em 3 dias até o 15 DAE, aplicando-se em cada irrigação uma lâmina líquida de $6 \mathrm{~mm}$. Posteriormente, a partir do 15 DAE, efetuou-se a irrigação somente quando o valor médio das leituras dos tensiômetros atingia o valor de $-35 \mathrm{kPa}$ (Marouelli et al., 1987).

A temperatura do ar, a umidade relativa e a lâmina de água evaporada foram registradas utilizando-se aparelhos instalados em um abrigo meteorológico, localizado no interior da casa de vegetação. A evaporação da água foi medida diariamente com um atmômetro de cápsula de porcelana porosa de $100 \mathrm{~mm}$ de diâmetro. As variações da temperatura do ambiente e do solo foram registradas em um termohigrômetro digital. A temperatura do solo foi obtida por meio de um sensor instalado na profundidade de $10 \mathrm{~cm}$ em uma das unidades experimentais. Durante os tratamentos, a temperatura do solo era obtida por meio de geotermômetros instalados na profundidade 
Tabela 1. Valores médios dos parâmetros biométricos obtidos de plantas de ervilha submetidas à inundação do solo no estádio vegetativo e reprodutivo da cultura de ervilha. Piracicaba, ESALQ,

\begin{tabular}{lcccc} 
Estádio & $\begin{array}{c}\text { Densidade } \\
\text { de raiz } \\
\left(\mathbf{k g ~ m}^{-3}\right)\end{array}$ & Altura $\mathbf{~ ( c m ) ~}$ & $\begin{array}{c}\text { Massa seca } \\
\text { área }(\mathbf{g})\end{array}$ & $\begin{array}{c}\text { Peso de } \\
\text { grãos }(\mathbf{g})\end{array}$ \\
\hline Vegetativo & $0,164 \mathrm{~b}$ & $63,95 \mathrm{a}$ & $17,13 \mathrm{a}$ & $30,1 \mathrm{a}$ \\
Reprodutivo & $0,193 \mathrm{a}$ & $62,40 \mathrm{a}$ & $15,76 \mathrm{~b}$ & $21,3 \mathrm{~b}$ \\
Testemunha & $0,264^{* *}$ & $66,75 \mathrm{~ns}$ & $18,53^{* *}$ & $44,0^{* *}$ \\
\hline C.V. $(\%)$ & 9,04 & 10,26 & 8,17 & 11,22 \\
\hline
\end{tabular}

Médias seguidas por letras distintas diferem entre si ao nível de $5 \%$ de probabilidade. ** significativo pelo teste $\mathrm{F}$ a $1 \%$ de probabilidade; ns = não significativo.



Figura 1. Efeito dos rebaixamentos do NF na densidade de raízes. Piracicaba, ESALQ, 2001. ** significativo ao nível de $1 \%$ de probabilidade.

de $10 \mathrm{~cm}$, em duas repetições de cada tratamento.

Os parâmetros produtivos analisados foram altura da planta (distância do solo até a borda superior da última folha estendida do ramo principal), massa seca da parte aérea da planta (pesagem de folhas, caule e ramos, após secagem complementar em estufa com circulação forçada de ar a $60-65^{\circ} \mathrm{C}$ até peso constante), densidade de raízes por planta (coleta de amostras no centro de cada unidade experimental na profundidade de 0-30 cm com auxílio de tubo metálico com diâmetro de $100 \mathrm{~mm}$ e $50 \mathrm{~cm}$ de comprimento), número de grãos produzidos e massa total de grãos por planta. Posteriormente, as amostras foram acondicionadas em recipiente juntamente com solução de $10 \%$ de álcool para a conservação das raízes. Para a separação das raízes utilizou-se o método de
Gottingen (Bohn, 1979). Após a separação, as raízes foram secas em estufa a $60^{\circ} \mathrm{C}$ e pesadas em balança de precisão de $0,1 \mathrm{mg}$.

\section{RESULTADOS E DISCUSSÃO}

Durante o desenvolvimento das plantas a temperatura do ar no interior da casa de vegetação apresentou variações extremas de 4,8 a $37^{\circ} \mathrm{C}$, sendo a temperatura média do ar, nesse período, de $22^{\circ} \mathrm{C}$. Durante os tratamentos as temperaturas médias foram de $22,4 \mathrm{e}$ $23^{\circ} \mathrm{C}$, no estádio vegetativo e reprodutivo respectivamente, abaixo do limite de $27^{\circ} \mathrm{C}$, onde a produção de grãos é muito prejudicada pela queda de flores e de vagens (Giordano, 1997). Quanto à temperatura do solo, verificaramse variações semelhantes à temperatura do ar, porém com menor amplitude. A temperatura máxima e mínima observadas no solo foram de 33 e $7^{\circ} \mathrm{C}$ respectivamente, e a temperatura média de $20^{\circ} \mathrm{C}$. A temperatura máxima do ar ocorria às 12 horas, enquanto no solo a máxima era registrada às 16 horas.

Durante os tratamentos a temperatura no solo mantinha-se 2 a $4^{\circ} \mathrm{C}$ menor do que a registrada nas unidades não inundadas. Segundo Silva (1986), a temperatura dos solos inundados tende a ser mais estável, em relação aos solos secos. Esse comportamento também foi observado em feijão (Silva, 1982) e milho (Cruciani, 1985). Em solos inundados, temperaturas elevadas favorecem o aumento da atividade microbiológica do solo reduzindo ainda mais a concentração de $\mathrm{O}_{2}$ disponível para a planta e aumentando as concentrações de elementos tóxicos como $\mathrm{CO}_{2}$ e etileno.

Em condições atmosféricas favoráveis à transpiração, o murchamento das folhas é o primeiro indício da deficiência de $\mathrm{O}_{2}$ no solo apresentado pelas plantas (Levitt, 1980), porém, quando as plantas foram submetidas ao encharcamento do solo no estádio vegetativo, não apresentaram sinais característicos da deficiência de $\mathrm{O}_{2}$, ao contrário do que observado quando os tratamentos ocorreram no estádio reprodutivo. Neste estádio as plantas submetidas ao excesso de água no solo apresentaram murchamento, amarelecimento e senescência prematura das folhas mais velhas, principalmente nas localizadas na ramificação principal. Estes sintomas, também foram observados por Cannell et al. (1979) em ervilhas submetidas à inundação total do solo por 24 horas, após o florescimento.

Observou-se maior suscetibilidade das plantas ao excesso de umidade no solo no estádio reprodutivo do que no estádio vegetativo. Neste caso, os efeitos da inundação na absorção de água e de nutrientes foram mais severos nas plantas após o florescimento. Segundo Belford et al. (1980) os efeitos da inundação são mais drásticos nas plantas velhas do que em plantas novas devido ao comprometimento do sistema radicular. No entanto, verificaram-se que os danos nas raízes foram significativamente maiores quando a hipoxia ocorreu no estádio vegetativo da cultura (Tabela 1). 
Observou-se evidência significativa do efeito negativo da inundação do solo na densidade de raízes em todos os tratamentos quando comparadas com as plantas controle, demostrando certa sensibilidade da cultura mesmo quando submetida a curtos períodos de hipoxia. Em plantas de algodão e soja a interrupção do crescimento e a morte do ápice radicular ocorreram quando submetidas a períodos de inundação de 3 e 5 horas, respectivamente (Huck, 1970).

A densidade de raízes variou linearmente com o período de submersão do sistema radicular da cultura (Figura 1). Os rebaixamentos do nível freático em 10 e $20 \mathrm{~cm}$ por dia apresentaram as menores densidades de raízes diferindo significativamente dos demais níveis.

A inundação do solo não afetou significativamente o crescimento das plantas, independente do estádio de desenvolvimento das mesmas (Tabela 1). Porém as plantas submetidas aos tratamentos no estádio reprodutivo apresentaram uma estatura inferior à observada nos tratamentos aplicados no estádio vegetativo. A altura média das plantas variou de 61 a $65 \mathrm{~cm}$ com o rebaixamento do NF em 10 e $60 \mathrm{~cm}$ por dia, respectivamente.

Os períodos de deficiência de $\mathrm{O}_{2}$ impostos em estádios de desenvolvimento da cultura de ervilha afetaram significativamente a produção de massa seca da parte aérea das plantas (Tabela 1), principalmente quando o estresse ocorreu após o florescimento. Neste estádio a massa seca acumulada foi $15 \%$ inferior à observada nas plantas controle. Já as plantas submetidas aos tratamentos no estádio vegetativo apresentaram uma redução de 7,5\%.

As menores produções de massa seca foram verificadas nas plantas submetidas ao rebaixamento do nível freático em 10 e $20 \mathrm{~cm}$ por dia, diferindo dos demais níveis. Assim como na densidade de raízes, a massa seca da parte aérea das plantas variou linearmente com os níveis de rebaixamento do NF, como apresentado na Figura 2.

No estádio reprodutivo, o murchamento, amarelecimento e senescência prematura das folhas, ocasionados provavelmente pela aeração deficiente e pelo aumento da concentra-

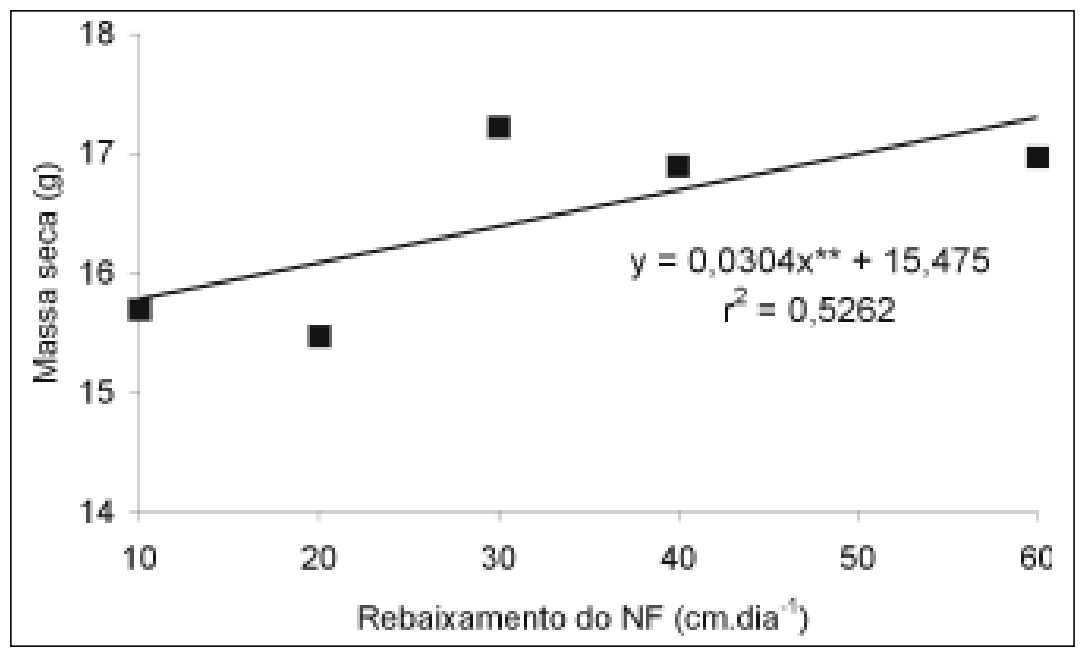

Figura 2. Efeito de níveis de rebaixamento do NF sobre a massa seca da parte aérea das plantas de ervilha. Piracicaba, ESALQ, 2001.

** significativo ao nível de $1 \%$ de probabilidade.

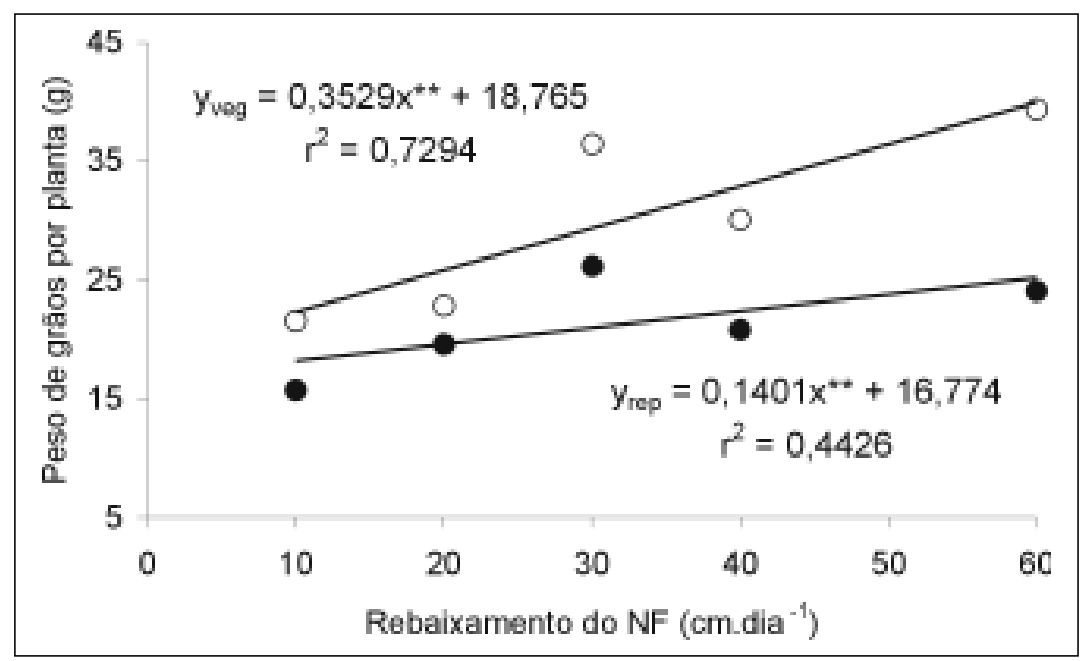

Figura 3. Efeito do rebaixamento do NF na produtividade das plantas de ervilha submetidas à inundação do solo no estádio vegetativo (O) e no reprodutivo (•).Piracicaba, ESALQ, 2001. ** significativo ao nível de $1 \%$ de probabilidade.

ção de substâncias tóxicas no solo, contribuíram para a redução substancial da massa seca da parte aérea das plantas. Resultados semelhantes foram observados em ervilha (Belford et al., 1980), em soja (Sallam e Scott, 1987; Sorte et al.,1995) e também em feijão (Singh et al., 1991).

A inundação completa do sistema radicular das plantas por seis horas foi suficiente para afetar a produtividade da cultura, principalmente quando a hipoxia ocorreu após o florescimento (Tabela 1). Neste estádio, a redução da produtividade foi superior a $50 \%$ em relação à produtividade média verificada nas plantas não inundadas. No estádio vegetativo a produtividade variou de 48 a $87 \%$ da obtida nas plantas controle, sendo as maiores reduções verificadas nos tratamentos V10 e V20. O manejo do nível freático não minimizou as reduções de produtividade quando a inundação do solo ocorreu no estádio reprodutivo; entretanto, no estádio vegetativo, os rebaixamentos do nível freático em profundidades superiores a $20 \mathrm{~cm}$ por dia ocasionaram perdas de $20 \%$. Em ambos estádios, a produtividade variou linearmente em relação aos 
níveis de rebaixamento do NF, como apresentado na Figura 3.

Os resultados indicam que os efeitos dos tratamentos na produtividade foram proporcionais ao tempo de permanência do sistema radicular submerso e variaram de acordo com o estádio de desenvolvimento da cultura, corroborando com afirmações de Kawase (1981) e Kramer (1983). A drástica redução da produtividade no estádio reprodutivo está relacionada com as alterações verificadas nas plantas principalmente com a redução da área fotossinteticamente ativa da planta ocasionada pelo amarelecimento e senescência das folhas (Wolfe, 1988).

\section{LITERATURA CITADA}

BELFORD, R.K.; CANNELL, R.Q.; THOMSON, R.J.; DENNIS, C.W. Effects of waterlogging at different stages of development on the growth and yield of peas (Pisum sativum L.) Journal of the Science of Food and Agriculture, v.31, p.857-869, 1980.

BOHN, W. Methods of studing root systems. Berlin: Springer-Verlag, 189 p. 1979.

BRADFORD, K.J.; YANG, S.F. Physiological responses of plants to waterlogging. HortScience, v.16, n.1, p.25-30, 1981.

CANNELL, R.Q.; GALES, K.; SNAYDON, R.W.; SUHAIL, B.A. Effects of short-term waterlogging on the growth and yield of peas (Pisum sativum L.). Annals of Applied Biology, v.93, n.3, p.327-335, 1979.

CARVALHO, E.M.; PIRES, T.E.; SANTOS, M.M.; FELIPE, P.M. Aproveitamento atual de várzeas sistematizadas. Informe Agropecuário, v.6, n.65, p.14-23, 1980.
CRUCIANI, D.E. Caracterização agronômica do coeficiente de drenagem para a elaboração de projetos com cultura de milho (Zea mays, L.). ITEM. Irrigação e Tecnologia Moderna, v.22, p.28-31, 1985.

FERREIRA, F.A.; GARRIDO, M.A. Olericultura Informe Agropecuário, v.6, n.65, p.54-56, 1980. GIORDANO, L.B. (Coord.) Cultivo da ervilha (Pisum sativum L.). Instruções Técnicas, n.1. Brasília: EMBRAPA, CNPH, 1997. 20 p.

GLINSK, J.; STEPNIEWSKI, W. Soil aeration and its role for plants. CRC Press Inc, Florida. 228 p. 1986.

HUCK, M.G. Variation in taprootelogation rate as influenced by composition of the soil air. Agronomy Journal, v.62, p.815-818, 1970.

JACKSON, M.B.; KOWALEWSKA, A.K.B. Positive and negative messages from roots induce foliar desiccation and stomatal closure in flooded pea plants. Journal of Experimental Botany, v.34, n.142, p.493-506, 1983.

KAWASE, M. Anatomical and morphological adaptation of plants to waterlogging. HortScience, v.16, n.1, p.30-34, 1981.

KRAMER, P.J. Water relations of plants. New York: Academic Press, 1983. cap.6, p.146-186: Development of root system.

LEVITT, J. Responses of plants to environmental stresses: water, radiation, salt and other stresses. New York: Academic Press, 1980. v.2, 607 p.

MC DONALD, G.K.; DEAN, G. Effect of waterlogging on the severity of disease caused by Mycosphaerella pinodes in peas (Pisum sativum L.). Australian Journal of Experimental Agriculture, v.36. n.2, p.219-222, 1996.

MAKASHEVA, R.K.H. The pea. Trad. de A. Balkema e A. Rotterdam. Lenigrado: Kolo Publ., $1973.218 \mathrm{p}$

MAROUELLI, W.A.; GIORDANO, L.B.; SILVA, W.L.C.; GUEDES, A.C. Época de paralização das irrigações em ervilha. Horticultura Brasileira, Brasília, v.5, n.1. p.18-20, 1987.
RODRIGUES, T.J.D.; RODRIGUES, L.R.A.; REIS, R.A. Adaptação de plantas forrageiras às condições adversas. In: SIMPÓSIO SOBRE ECOSSISTEMA DE PASTAGENS, 2., Jaboticabal, 1993. Anais... Jaboticabal: FUNEP, 1993. p.17-61.

SALLAM, A.; SCOTT, H.D. Effects of prolonged flodding on soybeans during early vegetative growth. Soil Science, v.144, n.1, p.61-66, 1987. SENA GOMES, A.R.; KOZLOWSKI, T.T. Responses of Malaleuca quinquenervia seedling to flooding. Plant Physiology. v.49, p.373-377, 1980.

SILVA, A.R. Tolerância das plantas ao encharcamento. In: SIMPÓSIO SOBRE ALTERNATIVAS AO SISTEMA TRADICIONAL DE UTILIZAÇÃO DAS VÁRZEAS DO RIO GRANDE DO SUL, 1., Porto Alegre, 1986. Anais... Brasília: PROVÁRZEAS;PROFIR, 1986. p.166-181.

SILVA, E.L. Suscetibilidade do feijoeiro (Phaseolus vulgaris L.) cv. Goiano precoce, a inundações temporárias do sistema radicular em diferentes fases do seu ciclo vegetativo. 1982, 77 p. (Tese mestrado), ESALQ, USP. Piracicaba.

SINGH, B.P.; TUCKER, K.A.; SUTTON, J.D.; BHARDWAJ, H.L. Flooding reduces gas exchange and growth in snap bean. HortScience, v.26, n.4, p.372-373, 1991.

SORTE, N.V; RAUT, J.S.; DEOTALE, R.D.; PATEL, M.C.; KATEKHAYE, S.D. Effect of waterlogging on soybean at critical growth stages. Journal of Soils and Crops, v.5 n.2, p.141-144, 1995.

TU, J.C. Effects of soil compaction, temperature, and moisture on the development of the Fusarium root rot complex of pea in southwestern Ontario. Phytoprotection, v.75, n.3, p.125-131, 1994.

WOLFE, D.W.; HENDERSON, D.W.; HSIAO, T.C.; ALVINO, A.L. Interactive water and nitrogen effects on senescence of maize: I. Leaf area duration, nitrogen distribution, and yield. Agronomy Journal, v.80, p.859-864, 1988. 